\title{
THE MANAGEMENT OF INVASIVE ALIEN PLANTS IN SOUTH AFRICA: STRATEGY, PROGRESS AND CHALLENGES
}

\author{
Brian W. van Wilgen, Centre for Invasion Biology, Department of Botany and Zoology, Stellenbosch University, \\ Private Bag XI, Matieland, 7602, South Africa; email: bvanwilgen@sun.ac.za
}

Keywords: biological invasions, biological control, conservation triage, regulation, Working for Water

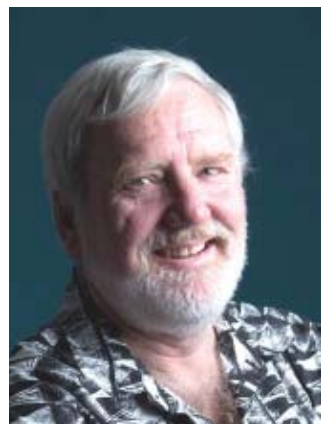

Brian W. van Wilgen

\section{Introduction}

Almost 900 species of alien plants have escaped cultivation and established populations in the wild in South Africa. About two third of these established alien species have become invasive, spreading into natural ecosystems. Many of them still have relatively restricted distributions in South Africa, but a growing number are becoming alarmingly widespread. These widespread species include many alien trees, such as pines (Pinus species), wattles (Acacia species) and mesquite (Prosopis species), as well as a host of shrubby, herbaceous and succulent species (Figure 1). In South Africa, alien plants are estimated to cover almost $7 \%$ of the country, and many species are now entering a phase of exponential growth. This problem has been recognised for over a century in South Africa, mainly because of the negative impact that alien plants have had on rangelands utilised for livestock production (Moran et al. 2013). However, it was the realization that alien plants, and especially alien trees, were responsible for the reduction of streamflow from water catchment areas that triggered a large expansion in control efforts in 1995 (van Wilgen \& Wannenburgh 2015). This article provides a brief description of the policies and strategies adopted in South Africa to address this problem, reviews the progress that has been made with control efforts, and outlines the main challenges that face the managers of alien plant control projects.

\section{Policy and strategy}

South Africa has adopted a diversified approach to the control of invasive alien plants. The approach is supported by legisla-

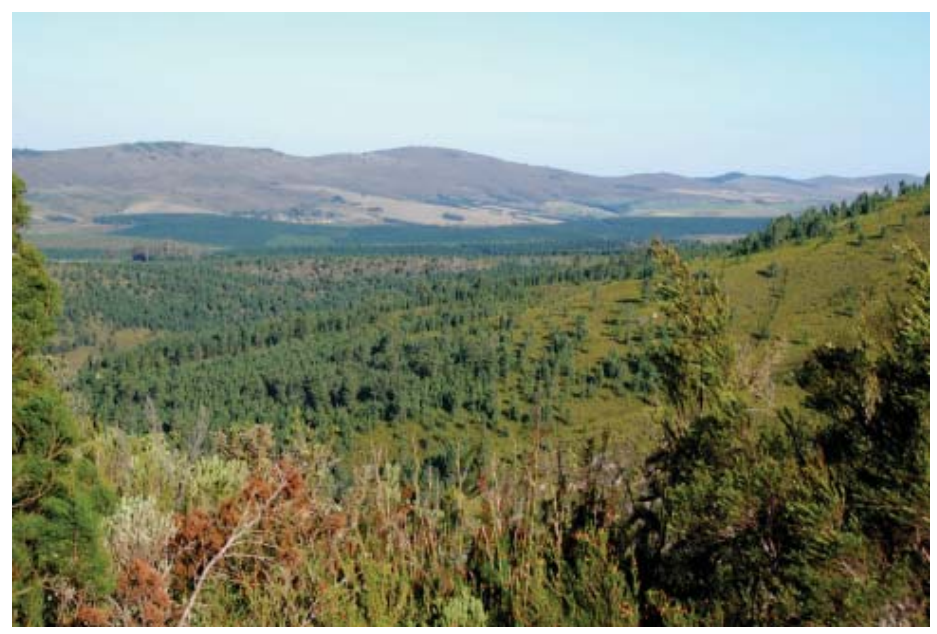

Figure I. Pine trees invading a fynbos (Mediterranean-climate shrubland) area. Several species of invasive pine trees have major impacts by reducing water resources from fynbos catchments, displacing globally unique biodiversity, and increasing fire hazard.

tion, and government funding is provided to address a range of aspects. Ultimately, the goal of these interventions is to reach a "maintenance level" for as many species in as many localities as possible (although this goal is seldom explicitly stated). The concept of a maintenance level recognises that, for many invasions, eradication is infeasible, but that the problem can be reduced to a level where the negative impacts are negligible and control costs are relatively low in perpetuity. The most important features of South Africa's approach to invasive alien plant management are outlined below.

Regulation of invasive alien plant species. The management of invasive alien plant species is regulated under a national law that provides for the management and conservation of biodiversity, the protection of priority species and ecosystems, and the sustainable use of indigenous biological resources. The regulations, published in 2014, list 379 alien plant species, divided into three categories to accommodate invasive species that are also useful. The first category lists weed species that have no value, must be controlled, and may not be owned or traded. The second category lists invasive alien species with commercial value, and that may only be owned or traded with a permit; permits prescribe the responsibilities of the permit-holder in terms of preventing spread. The third category lists invasive alien species with ornamental, historical or aesthetic value, that are tolerated under certain conditions, but that may not be traded or replaced. All landowners are required to take reasonable steps to control species in the first category, as well as species in the other two categories unless they have a permit. Failure to comply with 
the regulations is punishable by large fines, or even imprisonment, although there have been no prosecutions to date. These regulations are innovative in that they go beyond the requirement to control only recognised weed species, and cater for more contentious groups of plants that are normally not included in national legislation.

Detection, assessment and eradication. The regulations outlined above also divide the first category of invasive alien plants species into two subcategories, namely species with restricted distributions that potentially could be eradicated, and those that are more widespread, and where eradication is not an option. The term "eradicate" refers to the removal of all individuals and propagules from a specified area (in this case South Africa or any one of its offshore islands). In 2008, the South African government established a unit designed to (1) detect and document new invasions, (2) provide reliable assessments of the risks posed by the species concerned; and (3) to provide the cross-institutional coordination needed to implement national eradication plans (Wilson et al. 2013). To date, 32 potential alien plant eradication projects have been identified in South Africa. Of these projects, 24 are under consideration, pending the outcome of a risk analysis or the development of a detailed plan, and eight are ongoing. Historically (i.e. prior to 2008), three eradication attempts have failed (against Opuntia aurantiaca, jointed cactus; Solanum elaeagnifolium, silver-leaf bitter apple; and Alhagi camelorum, camel thorn bush), and there has not yet been a successful alien plant eradication project. The hope is that adopting a more systematic approach to these projects will ultimately lead to successful eradications.

Mechanical and chemical control. Most of the management of invasive alien plants in South Africa over the past 20 years has been undertaken as part of a large, national-scale, government-sponsored program termed 'Working for Water' (van Wilgen \& Wannenburgh 2016). This initiative combines mechanical and chemical control of all invasive alien plant species in targeted areas with the provision of employment to people from impoverished rural communities as its main thrust. The funding for control operations is channelled through the Department of Environment Affairs to a series of implementing agents. These include, among others, government departments, provincial nature conservation authorities, municipalities, irrigation boards, South African National Parks, and the South African National Defence Force. In turn, implementing agents appoint contractors who carry out clearing and follow-up operations. The methods used are deliberately labour-intensive, given that funding in support of this work is sourced from poverty-relief budgets that aim to create employment and developmental opportunities (Figure 2).

Biological control. Weed biological control is used extensively in support of labour-intensive containment and control efforts, and it has been responsible for some of the most noted successes in the implementation of alien plant control in South Africa. To date, biological control agents (host-specific insects, mites, or pathogenic fungi) have been released against 60 invasive alien plant species in South Africa (Klein 2011; Zachariades et al. 2017). In addition, agents are mass-reared in order to expedite control. Mass-rearing involves the establishment of a breeding facility, and a programme of targeted distribution of agents to field-sites.

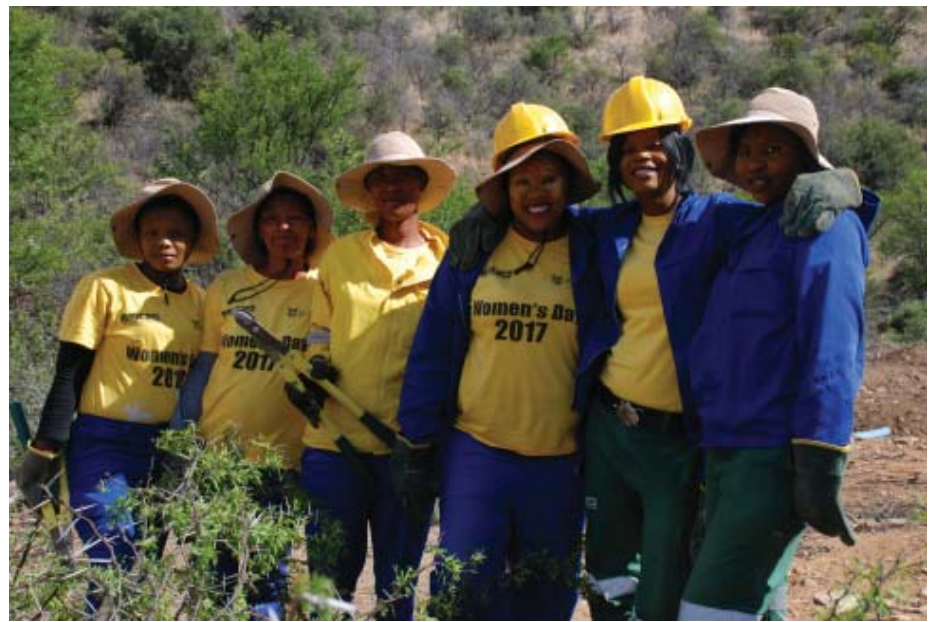

Figure 2. Women from rural communities employed to clear invasive alien plants as part of the Working for Water programme.

Research. Research is an essential component of the overall strategy needed to deal with invasive alien species, both to generate knowledge in support of management, and to build capacity through the training of post-graduate students. A range of science councils, universities and consultants have been funded from a variety of sources to conduct research over the past two decades, and this effort has made a large contribution to understanding the problem in South Africa (van Wilgen, 2004; Moran et al. 2011; van Wilgen et al. 2016a). In 2004, the South African Department of Science and Technology, through the National Research Foundation, established a Centre of Excellence for Invasion Biology (van Wilgen et al. 2014). Core team members of this centre are located at several universities in South Africa, with the aim of concentrating and strengthening existing capacity and resources to address the issue of biological invasions, by enabling researchers to collaborate across disciplines and institutions on long-term projects.

\section{Assessment of progress}

It would be premature to assess the effect of the current regulations, as they were only introduced three years ago. Similarly, most eradication projects have been initiated only recently, and the successful achievement of eradication can take a long time. In addition to this, our ability to assess progress with alien plant control programs is bedevilled by a lack of monitoring. This is due to various factors, including an absence of clear goals, and limited funding and capacity to conduct adequate monitoring. Arguably the most important factor that hinders monitoring, though, is the fact that most mechanical clearing projects have been funded to create employment. Government uses the number of employment opportunities created as the primary performance indicator for the program. The goal of maximising this number is achieved by employing as many people as possible in unskilled positions, leaving little capacity for planning and monitoring which would require trained, higher-paid personnel.

Despite this challenge, there has been considerable progress with some aspects. For example, the biological control of invasive plants has been notably successful. Of the 60 invasive 
plant species targeted for biological control thus far in South Africa, 15 species (eight succulent cacti, four aquatic plants, two herbs and one shrub species) are under complete control; and 19 species (nine tree or shrub species, eight succulent cacti, one aquatic plant and one herb) are under a substantial degree of control (Zachariades et al., 2017). Combining biological control with mechanical and/or chemical control has effectively reduced the populations of some of the most damaging invasive species, such as Hakea and Acacia species in the Western Cape (Esler et al., 2010; Moran \& Hoffmann, 2011), and Lantana and Opuntia species in the Kruger National Park (van Wilgen et al., 2017). The economic benefits of biological control have been substantial, with estimated cost to benefit ratios indicating that, for every one dollar invested into biological control, economic losses due to invasive alien plant invasions of between 8 and over 3,000 dollars have been avoided (van Wilgen \& De Lange 2011).

Despite a lack of effective monitoring, there are a small (but growing) number of studies that indicate, in some cases at least, that control interventions have been effective. Concerted efforts to remove invasive pine trees (and other species) from fynbos (shrubland) ecosystems have resulted in marked declines in the density of these species in the Berg River catchment (Fill et al., 2016; Figure 3), and on the Vergelegen Estate (van Rensburg et al., 2017). McConnachie et al. (2016) also demonstrated that the invaded area in the Hawequas mountains would have been almost $50 \%$ higher if there had been no control intervention. In savanna ecosystems, ongoing control has reduced the degree of invasion by a number of species (including Opuntia stricta, erect prickly pear, and Lantana camara, lantana, in the Kruger National Park (van Wilgen et al., 2017) and Chromolaena odorata, triffid weed, in the Hluhluwe-iMfolozi Park (te Beest et al.,

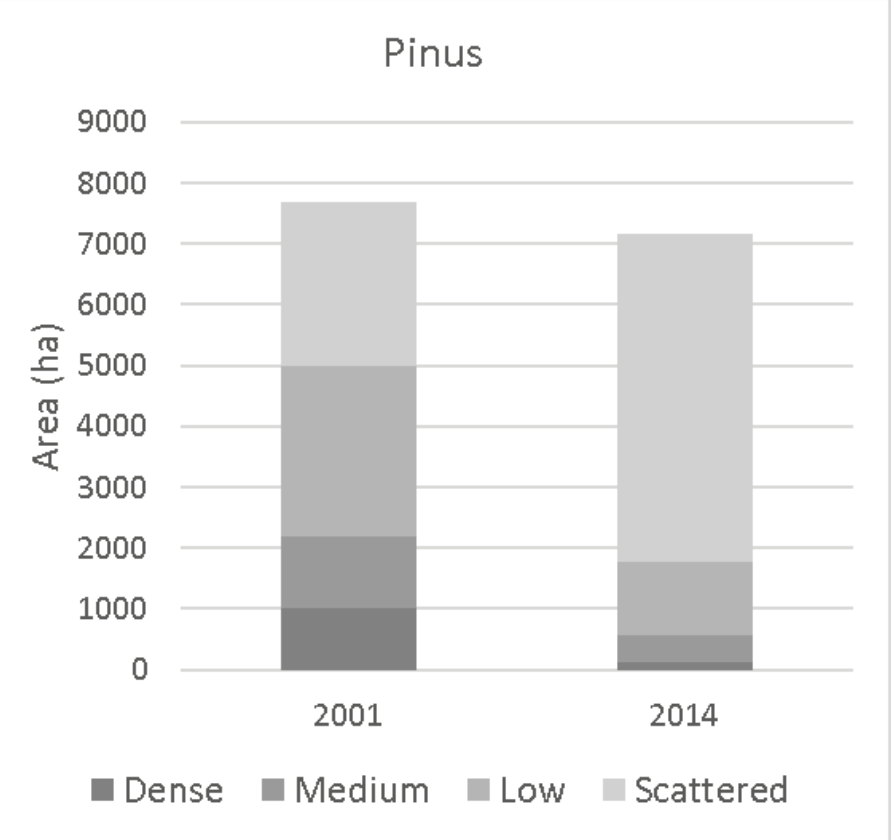

Figure 3. Area occupied by alien Pinus trees at different levels of cover in the 8000 ha Berg River catchment at the initiation of a control project in 200I, and after I 3 years of treatments in 2014. Cover levels are dense ( $>50 \%$ cover), medium ( $26-50 \%$ cover), low (6-25\% cover) and scattered $(0.5-5 \%$ cover). Figure redrawn from Fill et al. (2017).
2017; Figure 4). Thus, at a local scale, some control measures have demonstrably been effective. The bigger picture, however, is that despite generous funding, control operations only reach a small proportion of the estimated invaded area and invasions continue to grow (van Wilgen et al. 2012). In a recent assessment, Henderson \& Wilson (2017) found that there was an approximately $50 \%$ increase in the broad-scale documented range of alien plants between 2000 and 2016. In contrast, these authors also concluded that "some [invasive plant] species which have been the subjects of successful biological control programmes have shown very little expansion in their distribution" and "in general successful biological control seems to be associated with a reduction in the rate of spread". This again underlines the importance of maximising the use of this aspect of control wherever possible.

Research endeavours have also produced much in the way of new understanding and enhanced trained capacity. A holistic assessment of these achievements is not available, but a review of the achievements of the Centre for Invasion Biology at the completion of its first decade in 2014 revealed that the centre generated over 800 peer-reviewed publications, and produced almost 200 graduates at honours, masters and doctoral levels (van Wilgen et al. 2014), rising to 1467 publications and 300 graduates in 2017. The centre has, therefore, made a considerable contribution to building human capacity in the field of biological invasions, but this is an underestimate of the national situation. For example, research on biological control is conducted mainly by the Agricultural Research Council, and some universities (Moran et al. 2011), and the substantial outputs of these endeavours are in addition to those of the Centre for Invasion Biology.

\section{Outlooks for improving the efficiency of management}

South Africa's invasive alien species regulations require the production of a national status report every three years. These reports are required to assess the status of listed invasive alien species, and the effectiveness of control measures and of regulations. The first report will be submitted to government early in 2018 (van Wilgen \& Wilson 2018). This first status report

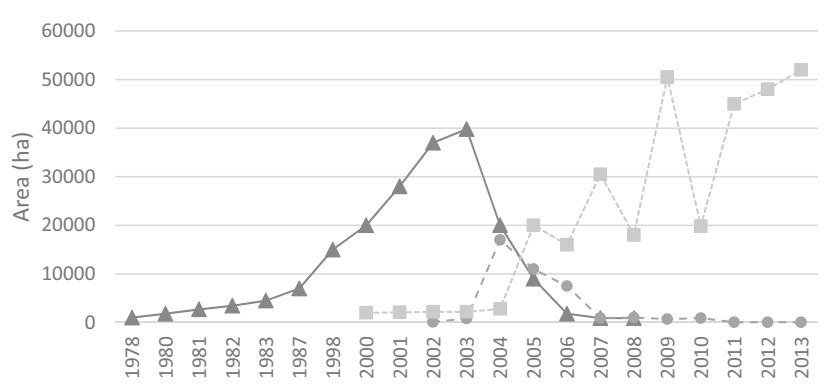

$\longrightarrow$ Invaded $\quad-\rightarrow$ - Initial ha cleared $\quad-\cdots-$ - Follow-up ha cleared

Figure 4. Area invaded by Chromolaena odorata in the 100000 ha Hluhluwe-iMfolozi Park, and areas cleared and followed up between 2000 and 20I3. Figure redrawn from te Beest et al. (2017). 
highlights the fact that limited progress has been made with the management of biological invasions at a national scale, and reviews some of the recommendations that have been put forward to increase the effectiveness of management.

If there is to be meaningful progress towards the goal of reducing invasions to a maintenance level for as many species, in as many localities as possible, then the limited funding will need to be focused on those places, and on those species, where this goal can be achieved. Three steps will be needed. First, there must be agreement on what the priorities are, and secondly an active choice will be needed with respect to which of the priority areas or species to target for control, i.e. it will be necessary to practice conservation triage (Bottrill et al. 2005). Finally, it will be necessary to improve on-the-ground management by promoting the use of best-practice methods. Prioritization exercises have already been initiated (e.g. Forsyth et al. 2012), and criteria have been selected to guide the identification of priority areas. It is proving challenging, however, to get managers to accept the need for triage, as it would require them to cease attempts to control invasions in some non-priority areas or species. For example, models predict that current control levels will fail to contain alien plants because they spread more rapidly than they are being removed (van Wilgen et al. 2016b). The chances of achieving control in some priority areas would increase if more funding were re-directed to those priority areas. A focus on priority species would also help to concentrate the scarce funds where they would be most effective. For example, fynbos shrublands are invaded by both pines and wattles, and available funding is divided equally between attempts to control these two groups (van Wilgen et al. 2016b). If the control effort were focussed on pines (which will eventually cover a much larger area if allowed to spread, Figure 1) instead of wattles (which are under more effective biological control), the eventual outcome would be far more favourable (van Wilgen 2016a, b). Finally, it will be necessary to align control efforts with agreed elements of best practice (including such approaches as the integrated use of fire, a greater use of power tools, and a focus on scattered rather than dense infestations, see Fill et al. 2016).

\section{Conclusion}

South Africa has been fortunate in that there is a high level of awareness around the issue of biological invasions, and this has resulted in a remarkable level of funding for an environmental issue in a developing country that has to meet substantial demands on funding for other priorities. This challenge has been partly overcome by linking alien plant control projects to employment creation. There have been some important successes (notably with biological control), but currently the funding is insufficient to address all problems everywhere. The existence of dual goals (ecological restoration and the creation of employment) is a double-edged sword. On the one hand, it is absolutely essential for the retention of the political support that ensures funding, but on the other it restricts the ability to focus funds where they are most needed for ecosystem restoration purposes. The biggest challenge in the future will be finding politically acceptable ways of focussing control efforts so that their efficiency can be maximised at a national scale. To fail to do this will simply see the problem run away from us, with dire consequences for the delivery of vital ecosystem services to future generations.

\section{References}

Bottrill, M.C., Joseph, L.N., Carwardine, J., Bode, M., Cook, C., Game, E.T., Grantham, H., Kark, S., Linke, S., McDonaldMadden, E. \& Pressey, R.L. (2008) Is conservation triage just smart decision making? Trends Ecol. Evol. 23, 649-654.

Esler, K.J., van Wilgen, B.W., te Roller, K.S., Wood, A.R. \& van der Merwe, J.H. (2010) A landscape-scale assessment of the longterm integrated control of an invasive shrub in South Africa. Biological Invasions 12, 211-218.

Fill, J.M., Forsyth, G.G., Kritzinger-Klopper, S., Le Maitre, D.C. \& van Wilgen, B.W. (2017). An assessment of the effectiveness of a long-term ecosystem restoration project in a fynbos shrubland catchment in South Africa. Journal of Environmental Management 185, 1-10.

Forsyth, G.G., Le Maitre, D.C., van Wilgen, B.W. \& O'Farrell, P.J. (2012). The prioritisation of invasive alien plant control projects using a multi-criteria decision model informed by stakeholder input and spatial data. Journal of Environmental Management 103, 51-57.

Henderson, L. \& Wilson, J.R.U. (2017) Changes in the composition and distribution of alien plants in South Africa: An update from the Southern African Plant Invaders Atlas. Bothalia 47(2), a2172. https://doi.org/10.4102/abc.v47i2.2172

Klein, H. (2011) A catalogue of the insects, mites and pathogens that have been used or rejected, or are under consideration, for the biological control of invasive alien plants in South Africa. African Entomology 19, 515-549.

McConnachie, M., van Wilgen, B.W., Gaertner, M., Richardson, D.M., Ferraro, P.J., Forsyth, A.T \& Cowling R.M. (2016) Using counterfactuals to evaluate the cost-effectiveness of controlling biological invasions. Ecological Applications 26, 475-483

Moran V.C., Hoffmann, J.H. \& Hill, M.P. (2011) A context for the 2011 compilation of reviews on the biological control of invasive alien plants in South Africa. African Entomology 19, 177-185.

Moran V.C., Hoffmann, J.H. \& Zimmermann, H,G. (2013) 100 years of biological control of invasive alien plants in South Africa: History, practice and achievements. S Afr J Sci. 109 (9/10), Art.\#a0022, 6 pages. http://dx.doi.org/10.1590/sajs.2013/a0022

Moran, V.C. \& Hoffmann, J.H. (2012) Conservation of the fynbos biome in the Cape Floral Region: the role of biological control in the management of invasive alien trees. Biocontrol 57, 139-149.

te Beest, M., Howison, O., Howison, R.A., Dew, A., Poswa, M.M., Janse van Rensburg, S. \& Terblanche, C. (2017) Successful control of the invasive shrub Chromolaena odorata in Hluhluwe-iMfolozi Park. In: Cromsigt, J.P.G.M., Archibald, S. and Owen-Smith (eds). Conserving Africa's mega-diversity in the Anthropocene: The Hlubluwe-iMfolozi Park story. pp. 358-382. Cambridge University Press, Cambridge, UK.

van Rensburg, J., Richardson, D.M. \& van Wilgen, B.W. (2017) The challenges of managing invasive alien plants on private land in the Cape Floristic Region: Insights from Vergelegen Wine Estate (2004-2015). Transactions of the Royal Society of South Africa 72, 207-216.

van Wilgen, B. W. (2004). Scientific challenges in the field of invasive alien plant management. South African Journal of Science 100, 19-20.

van Wilgen, B.W. \& De Lange, W.J. (2011). The costs and benefits of invasive alien plant biological control in South Africa. African 
Entomology 19, 504 - 514.

van Wilgen, B.W., Forsyth, G.G., Le Maitre, D.C., Wannenburgh, A., Kotzé, J.D.F., van den Berg, L. \& Henderson, L. (2012). An assessment of the effectiveness of a large, national-scale invasive alien plant control strategy in South Africa. Biological Conservation 148, 28 - 38.

Van Wilgen, B.W., Davies, S.J. \& Richardson, D.M. (2014). Invasion Science for society: A decade of contributions from the Centre for Invasion Biology. South African Journal of Science 110; Art. \#a0074, 12 pages. http://dx.doi.org/10.1590/sajs.2014/a0074.

Van Wilgen, B.W. \& Wannenburgh, A. (2016a). Co-facilitating invasive species control, water conservation and poverty relief: Achievements and challenges in South Africa's Working for Water programme. Current Opinion in Environmental Sustainability $19,7-17$.

van Wilgen, B.W., Fill, J.M., Baard, J., Cheney, C., Forsyth, A.T \& Kraaij, T. (2016b). Historical costs and projected future scenarios for the management of invasive alien plants in protected areas in the Cape Floristic Region. Biological Conservation 200, 168 177.

van Wilgen, B.W., Carruthers, J., Cowling, R.M., Esler, K.J., Forsyth, A.T., M. Gaertner, M., Hoffmann, M.T., Kruger, F.J., Midgley, G.F., Richardson, D.M., Palmer, G., Pence, G.Q.K., Raimondo, D., van Wilgen, N.J. \& Wilson, J.R.U. (2016). Ecological research and conservation management in the Cape Floristic Region between 1945 and 2015: History, current understanding and future challenges Transactions of the Royal Society of South Africa, 71, 207-304.

van Wilgen, B.W., Fill, J.M., Govender, N. \& Foxcroft, L.C. (2017). An assessment of the evolution, costs and effectiveness of alien plant control operations in Kruger National Park, South Africa. NeoBiota 35, 35-59.

van Wilgen, B.W. \& Wilson, J.R. (2018) The status of biological invasions and their management in South Africa 2017. South African National Biodiversity Institute, Kirstenbosch. ISBN: 978-1-928224-18-1.

Wilson, J.R.U., Ivey, P., Manyama, P. \& Nänni, I. (2013) A new national unit for invasive species detection, assessment and eradication planning. S Afr J Sci. 109 (5/6), Art. \#0111, 13 pages. http://dx.doi.org/10.1590/sajs.2013/20120111

Zachariades, C., Paterson, I.D., Strathie, L.W., Hill, M.P. \& van Wilgen, B.W. (2017). Assessing the status of biological control as a management tool for suppression of invasive alien plants in South Africa. Bothalia 47(2), a2142.https://doi.org/10.4102/ abc.v47i2.2142

Brian van Wilgen is a professor at Stellenbosch University, South Africa, where he is based at the DST-NRF Centre for Invasion Biology. He has four decades of experience as an applied ecologist, with a focus on two fields - fire ecology, and biological invasions. His particular interest is in the use of scientific understanding to improve ecosystem management. He has conducted work in southern and eastern Africa, and collaborated with others in Australia, Europe, North and South America, and on island ecosystems. He has served on numerous editorial boards, the most recent including the journals Conservation Biology, Fire Ecology, International Journal of Wildland Fire, and South African Journal of Science. He is author of over 200 publications, including three books and 125 peer-reviewed scientific papers.

Similar articles that appeared in Outlooks on Pest Management include - 